ported that some of the patients with monkeypox, none of whom had previously been vaccinated, gave an equivocal reaction to smallpox vaccine, a finding which would be expected from a closely related vaccine strain. ${ }^{5}$

Laboratory studies on the viruses so far isolated show that monkeypox strains are homogeneous but can be distinguished from other poxviruses by various laboratory tests. They appear to be more closely related to variola than to vaccinia or cowpox viruses. ${ }^{8}$ Further virological studies from the Congo disclosed the existence of monkeypox viruses in one clinically normal cynomolgus monkey and one normal chimpanzee, and further serological surveys for antibody to monkeypox in West and Central Africa have so far failed to detect any significant source of monkeypox virus infection. ${ }^{9}$ The true identity of these apparently rare cases might never have come to light but for the smallpox surveillance programme, and though the existence of a non-human reservoir of smallpox is possible the likelihood of this on present evidence seems remote.

\footnotetext{
1 Henderson, D. A., International Conference on the Application of Vaccines against Viral, Rickettsial, and Bacterial Diseases of Man, p. 139. Washington, Pan American (World Health Organization) Scientific Publication No. 226, 1970.

2 Henderson, D. A., Seminaire sur les Vaccinations en Afrique, Kampala 7-10 December 1971 , p. 50. (English text in preparation.)

3 Bulletin of the World Health Organization, 1972, 46, No. 5, 567.

Magnus, P. von, Anersen, E. K., Petersen, K. B., and Birch-Andersen, A., Acta Pathologica et Microbiologica Scandinavica, 1959, 46, 156.

5 Foster, S. O., et al., Bulletin of the World Health Organization, 1972, 46, 569.

Ladnyi, I. D., Ziegler, P., and Kima, E., Bulletin of the World Health Organization, 1972, 46, 593.

7 Eke, R. A., West African Medical fournal (New Series), 1972, No. 1, 21.

${ }^{8}$ Rondle, C. J. M., and Sayeed, K. A. R., Bulletin of the World Health Organization, 1972, 46, 577.

- Marennikova, S. S., Seluhina, E. M., Mal'ceva, N. N., and Ladnyi, I. D., Bulletin of the World Health Organization, 1972, 46, 613.

Bulletin of the World Health Organizat
10 British Medical fournal, 1972, 4, 253.
}

\section{Radiation Safeguards}

A deal o' rich confused feedin'-the Scotsman's judgement on the sheep's head-might aptly be applied to the World Health Organization's summary of arrangements for radiation protection. ${ }^{1}$ No environmental problem has ever been taken so seriously as the radiation hazard. Not surprisingly, the resulting pattern of regulations and advice is complicated.

Though dangers to staff and patients were recognized fairly early in the development of radiology, control measures were generally established by authoritative unofficial bodies. After the arrival of atomic energy in 1945 many countries introduced legislation, which inevitably overlapped existing codes of practice. During the past 25 years a measure of uniformity has been achieved in some directions through the activities of the International Commission on Radiological Protection. Most countries have adopted the commission's view that the maximum permissible dose for radiation workers should be 5 rems per year for the whole body, with relaxations for exposure limited to the skin, limbs, or other limited regions.

The methods of enforcing these regulations-and of ensuring the safety of patients-vary considerably among the 19 countries included in the new W.H.O. survey. In France, California, and the Netherlands physicians must have special training before being licensed to use radioactive isotopes for diagnostic purposes. In Switzerland chiropractors are allowed to use diagnostic $x$-ray equipment after passing a test of competence. In West Germany regulations for the surveillance of industrial radiation workers are relatively strict, but there are no legal restrictions on the use of radiation or isotopes in medicine; physicians have "complete freedom of choice regarding the nature of the radiation to which they expose their patients for diagnostic or therapeutic purposes." The British system is in principle rather similar, since the codes of practice governing medical, dental, and veterinary practice have no legal force; nor has the advice of the Medical Research Council's Isotope Advisory Panel. In practice, the educated concern of responsible professions is a better safeguard than detailed legislation.

1 Protection against Ionizing Radiation: A Survey of Current World Legislation. Geneva, World Health Organization, 1972.

\section{Functions of Thymus- dependent Lymphocytes}

Though lymphopoiesis was observed in the thymus early in the present century, a role for this organ in immunity was established only in 1961. J. F. A. P. Miller ${ }^{1}$ found that thymectomy of newborn mice led to depletion of circulating lymphocytes, failure to reject foreign skin grafts, and early death from infection.

Congenital absence of the thymus and parathyroid glands in man, apparently resulting from a failure in development of the third and fourth pharyngeal pouches, was described in $1965^{2}$ and has been seen several times since then. ${ }^{3-5}$ In all of these conditions there is severe impairment of cellmediated immune functions, including delayed hypersensitivity, contact sensitivity to dinitrofluorobenzene or other chemicals applied to the skin, rejection of foreign grafts, and capacity for a graft-versus-host reaction. In addition, children with defective function of the thymus show increased susceptibility to infections with certain viruses such as vaccinia, herpes simplex, and measles, or bacteria such as the Calmette-Guérin bacillus (B.C.G.) and to chronic mucocutaneous candidiasis. The selective depletion of thymus-dependent (or " $T$ ") lymphocytes, as in these conditions, contrasts with sex-linked hypogammaglobulinaemia, in which $T$ lymphocyte functions are normal, and with stem cell defects, in which both types of immune response are defective (the so-called Swiss type of agammaglobulinaemia).

Some lymphoid stem cells arising in the bone marrow migrate to the thymus and differentiate into thymusdependent or $T$ lymphocytes. These cells have little, if any, immunoglobulin on their surfaces and do not secrete immunoglobulin. However, they have certain antigens which are absent from other lymphocytes. These antigens and chromosome and radioactive markers have facilitated studies of lymphocyte-migration.

Thymus-dependent lymphocytes circulate through blood and lymph to the so-called thymus-dependent areas of lymph nodes, spleen, Peyer's patches, and other lymphoid aggregates. $T$ lymphocytes have relatively long lives (months or years) and constitute the bulk of recirculating lymphocytes. Each antigen specifically stimulates those $\mathbf{T}$ lymphocytes with receptors for that antigen, but not other T lymphocytes. Substances that stimulate mitosis, such as phytohaemagglutinin, stimulate $T$ lymphocytes, irrespective of their specific receptors for antigen, but they do not stimulate other types of lymphocytes. This sort of stimulation results in increased synthesis of RNA and protein in the 